\title{
Androgens and Immune Function in Male Alternative Reproductive Morphotypes of the Peacock Blenny Salaria pavo
}

\author{
Albert F. H. Ros* \& Rui F. Oliveira*, $\dagger$ \\ * Unidade de Investigação em Eco-Etologia, Instituto Superior de Psicologia Aplicada, Lisboa, Portugal \\ † Instituto Gulbenkian de Ciência, Oeiras, Portugal
}

\section{Correspondence}

Albert F. H. Ros, Unidade de Investigação em Eco-Etologia, Instituto Superior de Psicologia Aplicada, Rua Jardim do Tabaco 34, 1149-041 Lisboa, Portugal. E-mail: afhros@gmail.com

\section{Received: May 1, 2008}

Initial acceptance: June 18, 2008

Final acceptance: January 20, 2009

(K. Reinhold)

doi: 10.1111/j.1439-0310.2009.01636.x

\begin{abstract}
Species with alternative reproductive tactics offer the opportunity to analyse how behavioural and morphological traits are tuned to produce successfully competing phenotypes within one sex. In the teleost fish Salaria pavo, alternative reproductive tactics are sequential. The older ornamented males compete for access to females by guarding a cavity to which they attract females to spawn. Ornamented males that are found without a nest are called 'floaters'. Younger mature males which are too small to compete with nest-holders attempt to 'sneak' as female mimics into successful nests and release their sperm to fertilize freshly spawned eggs. The alternative tactics in S. pavo are associated with different levels of the androgens testosterone and 11 -ketotestosterone, which have been found to suppress immune function in several teleost fish. A field study was carried out to analyse the relationship between these reproductive tactics, androgens and blood levels of lymphocytes as a monitoring method of immune function. We expected highest investment in the immune system in sneakers because these have the lowest androgen levels and functionally because investing in self-maintenance increases their future prospect to switch tactic and to reproduce as a nest-holder. Indeed, the relative count of lymphocytes correlated negatively with body size and thus was highest in sneakers and lowest in nest-holders. In concordance, 11-ketotestosterone and testosterone levels were found to be higher in floaters and nest-holders than in sneakers. However, no correlation was found between individual levels of testosterone or 11-ketotestosterone and lymphocytes. Thus, a trade-off between reproductive traits associated with high androgen levels and immunocompetence might exist at the level of alternative tactics but this might not be explained by acute immunosuppressive effects of circulating androgens.
\end{abstract}

\section{Introduction}

To maximize reproductive output, individuals engage in energetically costly competition for mates and resources (Andersson 1991; Lailvaux \& Irschick 2006). This creates a life-history trade-off between the investment of resources in current reproduction vs. self-maintenance processes such as growth and survival. In many species, males of lower competi- tive ability reproduce using alternative reproductive tactics (ARTs) that exploit the reproductive investment of resource holding males (see Oliveira et al. 2008b for examples on different taxa). ARTs can be fixed for life or plastic in which case individuals might switch between tactics (i.e. parasitic vs. bourgeois) during their life (Taborsky 2008). In the later case, the most common pattern is the occurrence of sequential tactics where individuals switch tactics in 
a condition-dependent fashion. For example, males can reproduce using the parasitic tactic when younger/smaller and switch irreversibly to a bourgeois tactic when older/larger (Taborsky 2008). As in this scenario the prospects for future reproduction differ between ARTs, the trade-off between reproduction and self-maintenance in breeding individuals is expected to be different between tactics as well.

Survival depends to an important extent on the protective effects of the immune system against pathogen infections (Watts et al. 2001). However, immune responses are energetically costly and have been found to trade-off with reproduction (van Noordwijk \& de Jong 1986; Sheldon \& Verhulst 1996; Deerenberg et al. 1997; Demas 2004). Furthermore, sperm cells which are non-self can be the target of immune responses and this might result in lower sperm quality (Folstad \& Skarstein 1997). Therefore, in species with sequential ARTs it is expected that bourgeois males would be more prone to sacrifice their immunocompetence for an increase in reproductive potential than the younger parasitic males which relatively have higher future reproductive prospects. At a mechanistic level, androgens have been proposed as mediators of this trade-off in resource allocation between current reproduction and survival because of their suppressive effect on the immune system on one hand and to their constitutive effect on secondary sex characters, spermatogenesis and reproductive behaviour on the other hand (immunocompetence handicap hypothesis, Folstad \& Karter 1992; Folstad \& Skarstein 1997). The immunosuppressive effect of androgens has been tested for a wide range of taxa resulting in tenuous support for birds and mammals (Roberts et al. 2004; Viney et al. 2005; Miles et al. 2007). Teleost species have been studied to a less extent, but the available studies show relatively strong androgen-immune interactions (Robertson 1961; Slater et al. 1995; Law et al. 2001; Ros et al. 2006b; Kurtz et al. 2007).

Androgens also play an important role in the differentiation of ARTs in fishes (reviewed in Oliveira 2006). In particular, 11-ketotestosterone (KT), which is the most potent androgen in teleosts (Borg 1994; Oliveira \& Gonçalves 2008), has consistently been found to be higher in bourgeois than in parasitic males in different fish species with ARTs (reviewed in: Brantley et al. 1993; Oliveira 2006). Moreover, KT has been shown to induce secondary sexual characteristics that are expressed in bourgeois males but not in parasitic males. KT is metabolized from testosterone $(\mathrm{T})$ which in fish is not systematically different between tactics (Oliveira 2006; Oliveira et al. 2008a). The role of $\mathrm{T}$ in the expression of ARTs is less clear. No consistent pattern emerges from a comparative survey of circulating $\mathrm{T}$ levels between parasitic and bourgeois males (Brantley et al. 1993; Oliveira 2006; Oliveira et al. 2008a). The decoupling of the parasitic breeding tactic from androgen levels suggests that the costs of reproduction in parasitic males become independent of the deleterious effects of androgens on immune function.

In this paper, we compare androgen levels and immune parameters between different male reproductive tactics in a teleost species with sequential ARTs, the peacock blenny (Salaria pavo). This species inhabits the rocky shores of the Mediterranean Sea and adjacent North-Atlantic area (Zander 1986). Males nest in crevices and attract females to their nests where spawning takes place and parental care is exclusively provided by the males. Within its distribution range, this species has colonized several coastal lagoons where adequate hard substrates to serve as nest sites are usually very scarce. This scarcity of nest sites leads to an increase in competition for nests among breeding males which may favour the evolution of parasitic reproductive tactics. In fact, in these lagoon populations sequential reproductive ARTs have been described with younger and smaller males adopting a parasitic tactic during their first breeding season (Ruchon et al. 1995; Gonçalves et al. 1996). Parasitic males of this species are of a different morphotype than bourgeois males because they lack secondary sex characters, such as the sexpheromone producing anal gland and the head crest, and adopt female-mimicking behaviour and female nuptial colouration to gain access to the nests defended by older and larger bourgeois males (Gonçalves et al. 1996, 2003). These parasitic males called 'sneakers' have fully developed male gonads which relative to body size are larger than those of bourgeois males (Gonçalves et al. 1996). Because of the scarcity of nest sites, a surplus of bourgeois males act as floaters trying to take-over nests or adopting nests that become vacant (alloparental care is common in this species). Thus, floaters are in the same life-history stage as nest holders but are currently not reproducing. Bourgeois males have higher $\mathrm{T}$ and $\mathrm{KT}$ levels than parasitic males (Oliveira et al. 200la,b; Gonçalves et al. 2008). An ongoing mark-recapture study has shown that males marked as sneakers on one breeding season are recaptured as nest-holders (bourgeois tactic) on subsequent breeding seasons, which indicates that these two ARTs are sequential and irreversible (T. Fagundes, D. Gonçalves and 
R. Oliveira, unpubl. data). The occurrence of these three male types, sneakers (parasitic tactic), nestholders (bourgeois tactic) and floaters (bourgeois tactic currently not breeding), offers the possibility to test the ultimate and proximate predictions considering the immune system described above on differential life-history trade-offs between different reproductive tactics. More specifically we will test the following predictions:

1. Ultimately: tactics that have relative high current reproductive success in comparison with expected future reproductive success should allocate least in survival and thus in the immune system: thus nestholders were expected to be more immunosuppressed than sneakers and floaters.

2. Proximately: high androgen levels were expected to be immunosuppressive and thus tactics that express secondary sex traits associated with high androgen levels: floaters and nest-holders were expected to be more immunosuppressed than sneakers.

\section{Methods}

\section{Study Area and Sampling Procedure}

This study was conducted on free-living adult S. pavo males on a tidal sandflat area situated on the north coast of the Island of Culatra at the Ria Formosa Coastal lagoon area, Algarve, Portugal $\left(36^{\circ} 59^{\prime} \mathrm{N}\right.$, $7^{\circ} 51^{\prime} \mathrm{W}$ Algarve, Portugal; for a detailed description of the area see Almada et al. 1994). The sandflat is part of the Ria Formosa National Park (Ramsar RS212).

Fish were collected on the years 2005 (75) and 2006 (48) at the peak of the breeding season (Jun. and Jul.), which last from Apr. to Sep. (Almada et al. 1994). Individuals were captured with a hand net during low tide when the breeding area stays emersed. Immediately after catching, fish were anaesthetized with a light dose of MS222 (tricaine methanesulfonate; Sigma-Aldrich (Madrid, Spain); dilution 1:10 000) and their total length was recorded (to the nearest $0.1 \mathrm{~mm}$ ). Within $5 \mathrm{~min}$ after catching blood was drawn from the caudal vein with a 1 -ml heparinized syringe fitted with a 25 -gauge needle and placed in $1-\mathrm{ml}$ eppendorf tubes, and the time of day of blood sampling was recorded. Directly after taking the blood sample, a drop of blood was smeared over a slide and dried on air. Blood smears were stored in dried air at ambient temperature until further processing. The remaining blood was transported on ice to the lab, where it was centrifuged at $3000 \mathrm{~g}$ for $5 \mathrm{~min}$. Plasma was collected and stored at $-20^{\circ} \mathrm{C}$ until further processing. Especially in the case of sneaker males, the amount of blood sampled was too low for both analyses. Therefore, blood was drawn from six additional sneakers under comparable conditions to test whether androgen levels were different between sneakers and nest-holders. These samples were only used for hormonal analysis. At the end of the sampling procedure, all subjects were returned to the place of capture.

\section{Classification of Phenotypes}

We captured males of three different types: sneakers $(7.6 \pm 0.2 \mathrm{~cm}, \mathrm{n}=21)$, floaters $(10.4 \pm 0.2 \mathrm{~cm}$, $\mathrm{n}=35)$ and nest-holders $(11.3 \pm 0.1 \mathrm{~cm}, \mathrm{n}=67)$. Juvenile immature males were also present at the study site but were not included in our analyses. These male types were classified according to the state of development of their male ornamentation (i.e. two secondary sexual characters: a conspicuous head crest and the presence of anal glands), the presence of sperm and the context (i.e. guarding eggs in a nest or not) in which they were found (see Ruchon et al. 1995; Gonçalves et al. 1996). Males that did not express male ornamentation were classified either as immature males or as sneakers. Sneakers differ from immature males in that they have developed gonads and release sperm. Thus, sneakers were distinguished from immature males by gently pressing the ventral lateral surface of the abdomen after which sneakers visibly release sperm as opposed to immature males. Males that expressed male ornamentation were either classified as floaters or as nest-holders (see Oliveira et al. 200lb). We distinguished between them according to the presence of eggs at the place of capture and on their site of capture: floaters were not associated with a nest, while nest-holders were captured from a nest with eggs. Thus, males classified as floaters were not reproducing at the time of catching. These males might have just developed their male ornamentation and not yet engaged in sexual competition, or they might have reproduced as a nest-holder in the past and lost or abandoned their nest.

\section{Assessment of Immune Function}

Because S. pavo is a relatively small species, a relatively low volume of blood could be sampled. A pilot study to search for a method to test immunocompetence resulted in zero antibody responses in nest-holders that were vaccinated with SRBC (kindly provided by Dr. A. Bruno Soares, ISA, Universidade Técnica de Lisboa, Lisbon, Portugal). Unfortunately, the blood volume for sneakers was too low for the 
analysis of antibody titres (A. F. H. Ros, unpubl. results). Therefore, we choose to analyse relative numbers of lymphocytes from blood smears as alternative method for monitoring variation in the immune system (see also Nava et al. 2001). Interpretation of blood smears has been argued to be troubled by the response of circulating lymphocyte levels to infections, which would make a healthy immunocompetent animal difficult to distinguish from a diseased animal (Norris \& Evans 2000). Still, animals that have low relative counts of lymphocytes might be expected to be less able to mount immune responses than animals with high relative counts of these cells. For example, in a closely related species (Parablennius parvicornis) low levels of lymphocytes correlated with low antibody responses to vaccination with a novel antigen (SRBC, Ros et al. 2006a).

Blood smears were placed in methanol for $2 \mathrm{~min}$ followed by staining for $20 \mathrm{~min}$ in Giemsa's azur eosin methylene blue solution (1:10 dilution in buffer; Merck KGaA, Darmstadt, Germany). Blood smears were evaluated under a microscope (BX-50; Olympus, Tokyo, Japan) at $100 \times$ magnification. For each subject of 25 fields from randomly chosen places on the smear, all cell types were counted (approx. 150 total cell count per field). Lymphocytes were identified as small spherical cells with little cytoplasm. Granulocytes were scarce and left out of analyses (in bourgeois males: less than $0.1 \%$ of total blood cell count). We report lymphocyte counts as percentages of the total cell count (lymphocytes + granulocytes + thrombocytes + erythrocytes, see Ros et al. 2006a,b).

\section{Hormonal Analysis}

Androgen levels were analysed in plasma collected in 2006 only. To assess circulating levels of androgens by radio-immunoassay, the free steroid fraction was extracted with diethyl ether from plasma using the method described in Scott \& Vermeirssen (1994). Steroid residues were re-suspended in $1 \mathrm{ml}$ assay buffer and stored again at $-20^{\circ} \mathrm{C}$ until assayed for KT and T. For the quantification of KT, the antibody kindly donated by D. E. Kime was used, and its cross-reactions are described in Kime $\&$ Manning (1982). The antibody for $\mathrm{T}$ was purchased from Research Diagnostics (RDI-TRK2T2, Concord, NH), and the cross-reactivities provided by the supplier are $16 \%$ for $5 \alpha$-dihydrotestosterone, $1 \%$ for androstenediol, $0.4 \%$ for androstenione, $<0.1 \%$ for androsterone, $<0.1 \%$ for dehydroepiandrosterone, $<0.1 \%$ for progesterone, $0.001 \%$ for oestradiol and
$0.001 \%$ for cortisol/pregnenolone. For both KT and $\mathrm{T}$, intra-assay coefficients of variation were $5 \%$ and inter-assay coefficients of variation were $15 \%$.

\section{Ethical Note}

Blood sampling was carried out by a certified researcher by Direcção-Geral de Veterinária. Blood was sampled from fish that had reached a deep stage of anaesthesia. The cue for this stage was a total loss of equilibrium and reflexes to stimulation (Summerfelt \& Smith 1990). During anaesthesia, respiratory opercular movements were monitored. Fish were allowed to recover from anaesthesia in a small isolation aquarium before they were returned to the site of capture. All animals survived the experimental procedures. In other experiments (e.g. Ros et al. 2006a,b) no evident side effect of blood sampling were found. The experimental procedures have been reviewed by a veterinarian and comply with the Portuguese legislation for the use of animals in experimental research.

\section{Temperature Measurements}

The temperature to which the fish were exposed was estimated from hourly averages taken from a 'stowaway tidbit' temperature logger (onset, USA). This logger was mounted in a brick placed in the study area. During the reproductive period, this brick housed several nest-holders.

\section{Statistical Treatment and Data Analysis}

Variables did not significantly deviate from normality (Kolgomorov-Smirnov test, ns) and we used parametric statistics (Pearson's correlation, Student's ttest, ANOva). The one exception was the androgen levels of sneaker males which all fell under the detection limit of the assay. These data were truncated to this detection level and thus had no variance. To test significance for these data non-parametric tests were used (Fisher's exact test, binomial test). When using t-tests and ANOvAs, we checked for the equality of variances assumption by calculating the Levine statistic. In all analyses, this statistic was non-significant $(p>0.07)$. All analyses were carried out with the SPSS 15.0 package (SPSS Inc, Chicago, IL) and p-values represent two-tailed probabilities.

In all cases, blood samples were drawn during low tide and semi randomly (depending on order of capture) in regard to male categories. This ensured that comparisons between groups were not biased by the 
variation in environmental factors. In the data analysis, we checked for effects of two of these factors temperature and hour of day. To correct further analyses, residuals were used. Here, we subtracted one or two degrees of freedom from the corresponding statistics depending on the type of residual to correct for the addition of one (linear model) or two factors (quadratic model).

Alternative tactics in $S$. pavo are sequential and thus differ in both age and body size. In a closely related species, body size was found to be negatively correlated with leucocyte counts (Ros et al. 2006a,b). Unfortunately, the sequential reproductive tactics (sneakers to floater/nest-holder) in S. pavo showed too little overlap in body size to conduct statistical comparisons between groups with body size added as a covariate (see Fig. 3). Therefore, we conducted separate tests for examining: (1) the relationship between body length and lymphocyte levels (separate regression analyses); and (2) the relationship between alternative tactics and lymphocyte levels (one-way ANOvA).

Finally, we collected data on lymphocyte percentages during two reproductive seasons (year 2005 and 2006). Adding year as random factor in the analyses did not result in a significant year effect (ANCOVA, p > 0.20) and thus data of 2005 and 2006 were pooled.

\section{Results}

\section{Sampling Effects on Lymphocytes and Androgen} Levels

Fish were caught during low tide when the reproductive habitat was emersed and fish were easy to capture and handle. Because of the shifting time of low tide across different sampling days, this resulted in a wide variation in the hour of day in which blood samples were drawn. In the low tide refuge where we placed the temperature logger, mean temperatures (averaged over $1 \mathrm{~d}$ ) ranged between 20.7 and $24.7^{\circ} \mathrm{C}$ in Jun. and Jul. (average \pm SD: $22.7 \pm 1.1^{\circ} \mathrm{C}$, no significant correlation between temperature and date, Pearson's $r=0.16, p=0.2$ ). Between sampling points, temperatures ranged between 19 and $32^{\circ} \mathrm{C}$.

In our sample, sneakers were smallest (one-way ANOVA, $\mathrm{F}_{2,120}=80.3, \mathrm{p}<0.001$; Bonferroni post hoc comparisons $\mathrm{p}<0.001$ ) and their total length distribution showed little overlap with that of floaters and nest-holders (see Fig. 3). The size distributions of floaters and nest-holders overlapped with floaters being on average significantly smaller than nestholders (one-way ANOVA, Bonferroni post hoc comparison $\mathrm{p}=0.001)$.

To test possible effects of temperature and hour of day on the variation in the circulating levels of lymphocytes and androgens, a regression analysis was carried out. Sneakers were left out of this analysis, first because we had little data on androgen levels $(\mathrm{n}=6)$; and second because we expected differences in lymphocyte percentages between sequential tactics (sneaker vs. floater/nest-holders).

Lymphocyte percentages showed a linear increase with hour of day with no significant effect of temperature (Fig. lc; partial correlation controlled for the effect of total length: hour of day, $r=0.50$, $\mathrm{df}=90, \mathrm{p}<0.001$; temperature: $\mathrm{r}=-0.13, \mathrm{df}=90$, $\mathrm{p}=0.22)$. $\mathrm{T}$ levels showed an inverse second-order polynomial trend with hour of day, showing elevated levels after sunrise and before sunset (Fig. la; $\left.r^{2}=0.41, n=45, p<0.001\right)$. Although, the regression between KT and hour of day was not statistically significant (Fig. $\mathrm{lb} ; \mathrm{r}^{2}=0.043, \mathrm{n}=45$, $\mathrm{p}=0.40$ ), eight of nine samples taken between 10 and $17 \mathrm{~h}$ were lower than the mean (binomial test: $\mathrm{p}<0.02$ ) suggesting that a similar trend as found in $\mathrm{T}$ existed. KT and $\mathrm{T}$ levels were positively correlated (Pearson's $r=0.56, n=45, p<0.001$ ). The effect of time of day on androgen levels was not explained by the variation in temperature [effect temperature, corrected for multiple tests (2 hormones, time and temperature), $\mathrm{p}>0.10]$.

In further statistics, we controlled the influence of sampling hour by retaining the residuals from the regression analysis of hour and the response variables.

Interaction Among Reproductive Tactics, Lymphocytes and Androgen Levels

Both $\mathrm{T}$ and KT levels were found to be significantly lower in sneaker males (all values fell below the lower detection limit of the assay) than in floater and nest-holder males (Fig. 2a, b; <0.3 ng/ml: sneaker, T and KT, 6 of 6 ; floater + nest-holder, T, 2 of 45, KT, 3 of 45; Fisher's exact test: $\mathrm{p}<0.001)$. Both residual $\mathrm{KT}$ and residual $\mathrm{T}$ levels were higher in nest-holders than in floaters, though this was only statistically significant for KT (Fig. $2 \mathrm{a}, \mathrm{b}$; residual T: $\mathrm{t}_{43-2}=-2.01, \mathrm{p}=0.051$; residual $\mathrm{KT}$ : $\mathrm{t}_{43-2}=-2.29$, $p=0.027)$. As was predicted from these differences in androgen levels, lymphocyte percentages differed significantly among male types (ANOvA: $\mathrm{F}_{2,117-}$ $\left.{ }_{1}=14.3, \mathrm{p}<0.001\right)$. Post hoc comparisons revealed 
(a)

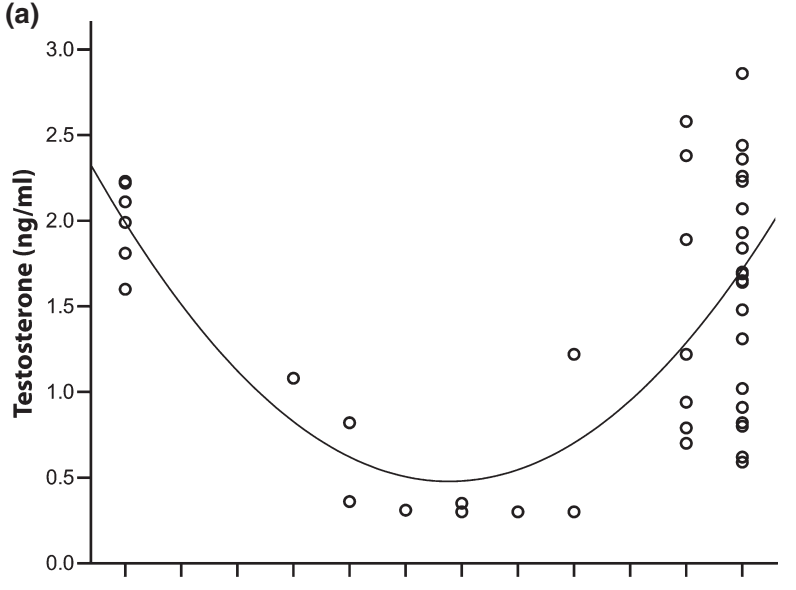

(b)

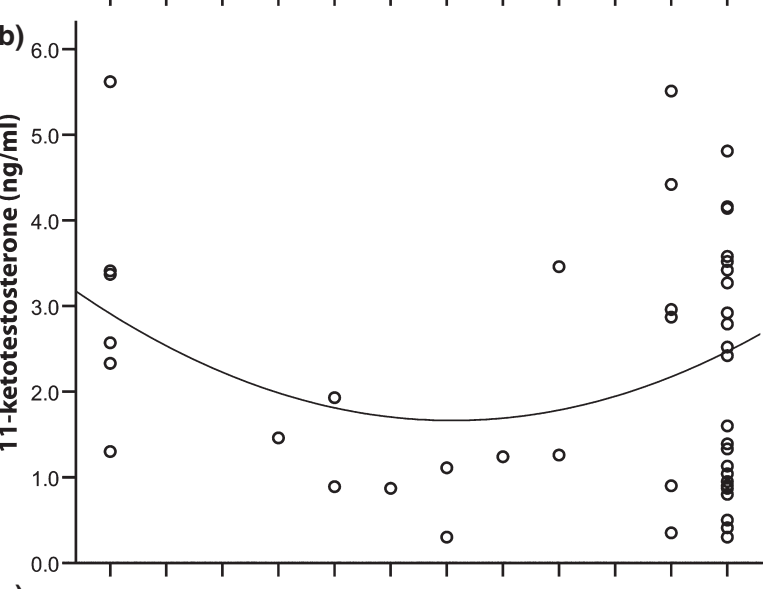

(c)

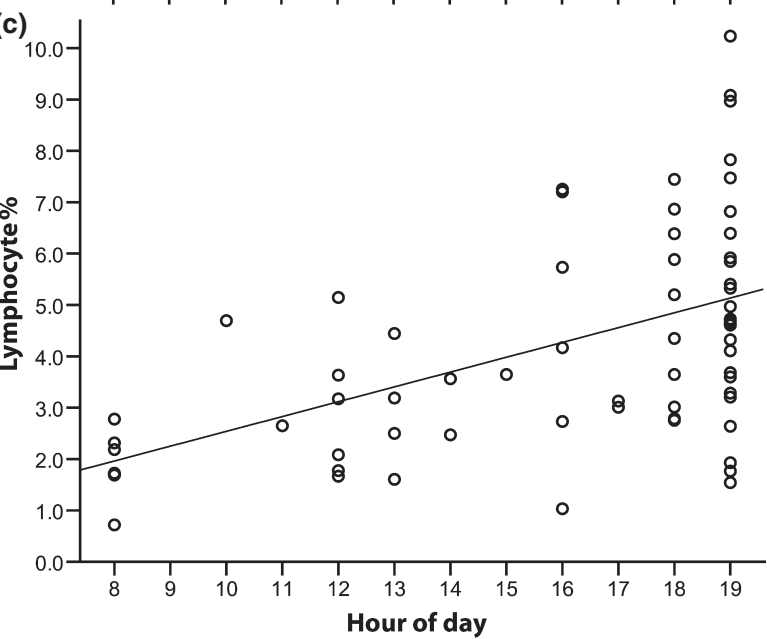

Fig. 1: Hourly changes in blood plasma levels of androgens and blood cell percentages of lymphocytes (lymphocyte cell count/total blood cell count) in Salaria pavo.

that sneakers had higher values than both nestholders and floaters (Fig. 2c; Bonferroni: sneaker vs. nest-holder: $\mathrm{p}<0.001$; sneaker vs. floater: $\mathrm{p}=0.004$; floater vs. nest-holder: $\mathrm{p}=0.16$ )

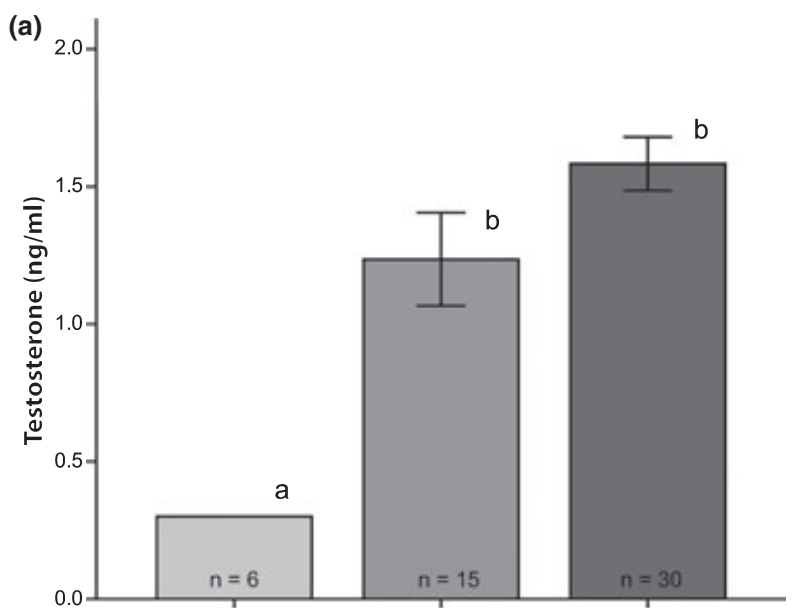

(b)
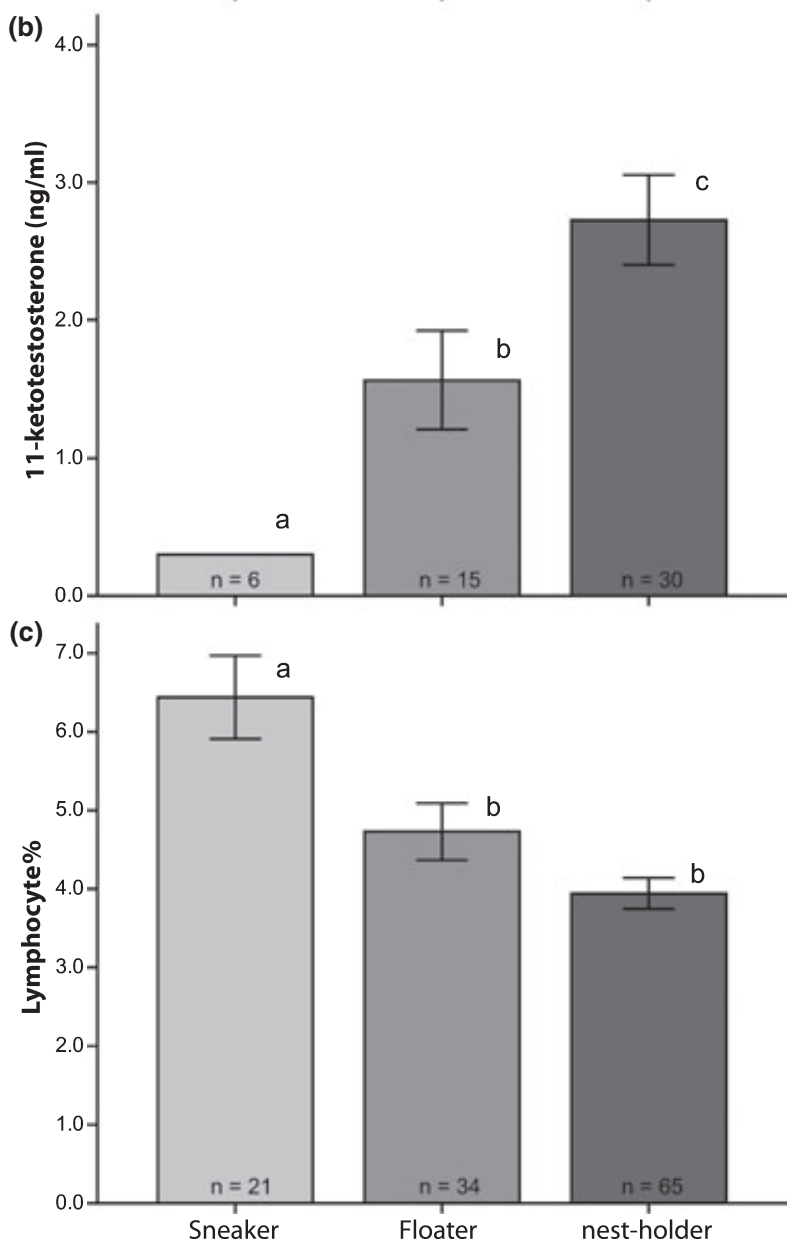

Fig. 2: Comparison of plasma levels of androgens (a, b) and blood cell percentages of lymphocytes (lymphocyte cell count/total blood cell count) (c) between males of different reproductive tactics in Salaria pavo. Light bars = sneakers, grey bars $=$ floaters, dark bars $=$ nestholders. Values shown are corrected for the correlation with hour of day (see Fig. 1). Different small letters notify significant differences between groups $(p<0.05) \cdot \bar{x} \pm$ SEM are given. 


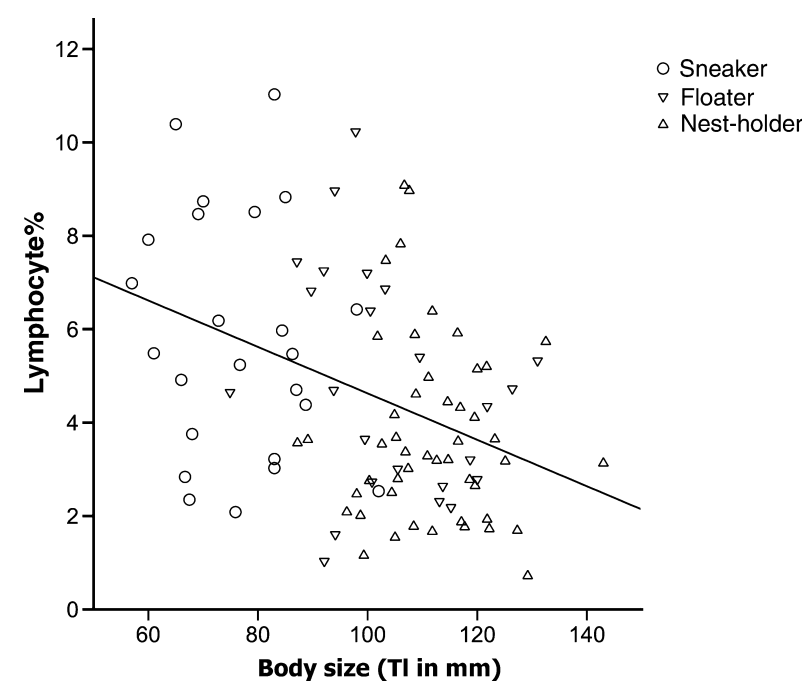

Fig. 3: Regression between blood cell percentages of lymphocytes (lymphocyte cell count/total blood cell count) and body size (total length) in Salaria pavo. The regression line is drawn only through data of floaters and nest-holders.

To test the possible relationship between residual lymphocyte percentages and body size, separate regression analyses for each tactic were carried out. The regression analyses was borderline significant for floaters only (Fig. 3; sneakers: $\mathrm{r}=-0.27, \mathrm{n}=21-1$, $\mathrm{p}=0.25$; floaters: $\mathrm{r}=-0.42, \mathrm{n}=34-1, \mathrm{p}=0.042$; nest-holders: $\mathrm{r}=-0.11, \mathrm{n}=65-1, \mathrm{p}=0.38$; $\mathrm{p}$-values corrected for Bonferroni). The negative relationship was significant when sneakers were left out of analyses $(r=-0.30, n=99-1, p=0.003)$.

Finally, the data of floaters and nest-holders were used to test for a possible relationship among T, KT and lymphocyte percentages. Partial regression analysis was used controlled for the effect of body size and hour of day. No significant negative correlation was found between leucocyte values and androgen levels $(\mathrm{T}: \mathrm{r}=-0.24$, df $=38, \mathrm{p}=0.14 ; \mathrm{KT}: \mathrm{r}=-0.08$; $\mathrm{df}=38, \mathrm{p}=0.61)$.

\section{Discussion}

Alternative reproductive male tactics of the peacock blenny differed significantly in blood levels of androgens and lymphocytes. Nest-holders and floaters (bourgeois males) had lower lymphocyte percentages and higher plasma levels of $\mathrm{T}$ and KT than the parasitic sneakers (see also Oliveira et al. 200la,b and Gonçalves et al. 2008). However, androgen levels (T and KT) did not show the expected negative correlation with lymphocyte percentages. Overall, these results are in agreement with data obtained from a related blenny species, the Azorean rock-pool blenny, P. parvicornis (Ros et al. 2006a,b), suggesting that a trade-off between androgen-dependent traits (morphotype) and immunocompetence may be present at the level of ARTs in blennies which is not likely explained by acute immunosuppressive effects of circulating androgens.

In the immunocompetence handicap hypothesis, Folstad \& Karter (1992) proposed that a trade-off between male sexual traits and parasite resistance might be the result of an immunosuppressive effect of the high androgen levels necessary for the production or maintenance of the sexual traits. Accordingly, experimental studies in a wide range of teleost species have found mostly immunosuppressive effects of $\mathrm{T}$ and KT, the latter of which facilitates the expression of secondary sexual characters in fish (e.g. Slater \& Schreck 1997; Ros et al. 2006b; Kurtz et al. 2007; but see Vainikka et al. 2005). However, individual $\mathrm{T}$ and KT levels appear not to be negatively correlated with proxy measures of immunocompetence (peacock blenny, S. pavo, this study; rock-pool blenny, P. parvicornis, Ros et al. 2006a; roach, Rutilus rutilus, Vainikka et al. 2004). Androgens are among many factors that regulate the immune system (Yada \& Nakanishi 2002) and that may explain the lack of a direct relationship between both measures. Furthermore, both androgen levels and lymphocyte percentages were found to have different daily fluctuations (see also Zohar \& Billard 1984). Such, intra-individual variation in lymphocyte and androgen levels, could mask possible significant inter-individual relationships between circulating lymphocyte and androgen levels. Without better information about what are the causes of these fluctuations (social factors, temperature, infections), it is difficult to select the best time for sampling (time of day, tidal period) or to correct both measurements of immunity and hormones to get representative individual values.

ARTs might be viewed as the outcomes of a natural experiment in which divergent suites of traits have been selected that promote the development of competitively reproducing individuals. One theme of such ARTs is that in most species bourgeois males have higher levels of androgens, in particular KT, than parasitic males (Oliveira 2006; Oliveira et al. 2008a). Concordant with the immunocompetence handicap hypothesis in this study and in the study on P. parvicornis (Ros et al. 2006a), androgen levels ( $\mathrm{T}$ and $\mathrm{KT}$ ) were found to be higher and lymphocyte percentages were found to be lower in bourgeois males, and in particular in the males that guard eggs 
(nest-holders), than in parasitic males. The effect of androgens on the immune system might not be acute, for example depending on changes in androgen receptors on lymphocytes (e.g. Slater \& Schreck 1998). Experimental treatment with slow releasing implants of $\mathrm{T}$ might be more comparable with the differences in androgen exposure between ART (see Ros et al. 2006b). Additionally, it cannot be ruled out that other factors correlated with ARTs might cause the variation in both androgen levels and the immune system. Such a causal factor can be social modulation. Androgen levels respond strongly to the social environment of the individual (Oliveira et al. 2005). Androgen levels have been found to increase in territorial males after being exposed to an agonistic challenge and are low in males isolated from such challenges. On the other hand, humoral immune responses to an immune challenge have been found to decrease in males exposed to social challenges (Dijkstra et al. 2007). Such effects of social modulation might be measurable in bourgeois males which defend a spawning site at which they are frequently challenged.

Another important factor, although not necessarily independent of changes in androgen levels, that may explain ART-related differences in immunocompetence is age. We found a negative correlation between lymphocyte levels and body size in S. pavo and a similar relationship was found for P. parvicornis (Ros et al. 2006a,b), while otolith data have shown that age and body size are tightly correlated in S. pavo (Gonçalves et al. 1996) and P. parvicornis (Santos et al. 1995). Salaria pavo sneakers with highest lymphocyte percentages are $1 \mathrm{yr}$ old whereas bourgeois males are 2-3 yr old (Gonçalves et al. 1996). With age animals accumulate immunological memory, i.e. the capacity to produce specific antibodies to the pathogens they have been exposed to. This mechanism allows an animal to respond more rapidly to subsequent infections by such pathogens and to neutralize it more efficiently than during the first infection with that pathogen (e.g. Klasing 2004). Most blennies stay year round in a relatively small area and thus older animals are likely to have been in contact with most of the pathogens in their environment. Thus, it may be less important to maintain the capacity to respond to new pathogens in older than in younger animals. If so suppression of immunocompetence might be less costly for the older nest-holders than for sneakers and ultimately this might influence age-dependent outcomes of a trade-off between investing in reproduction and in the immune system.
In two other teleost species, immunocompetence has been studied in the context of ARTs, the artic charr, Salvelinus alpinus and the corkwing wrasse, Symphodus melops. In both these species, lymphocyte levels were not found to be significantly different between the parasitic and the bourgeois tactic (Uglem et al. 2001; Liljedal \& Folstad 2003). Nevertheless in $S$. alpinus a similar trend was found as in the two blenny species. When the lymphocyte levels (non-corrected) of these species are compared in a meta-analysis (MIX, Bax et al., 2008) of ART (parasite vs. bourgeois) on lymphocyte levels this resulted in an overall effect size (Hedges's g) of 0.87 that was statistical significant $(\mathrm{z}=7.7, \mathrm{p}<0.001$; S. melops, Uglem et al. 2001: effect size $=-0.08, \mathrm{n}=49$, $\mathrm{p}=0.8 ;$ S. alpinus, Liljedal \& Folstad 2003: effect size $=0.41, \mathrm{n}=39, \mathrm{p}=0.2 ;$ P. parvicornis, $\mathrm{Ros}$ et al. 2006a,b: effect size $=1.24, \quad \mathrm{n}=195, \quad \mathrm{p}<0.001$; S. pavo, this study: effect size 0.96, $\mathrm{n}=120$, $\mathrm{p}<0.001)$. Even with the low number of studies the result is robust showing a high fail safe number (39 with a tolerance level of 30). However, the data shows a high heterogeneity (Cochran's Q = 18.6, $\mathrm{p}<0.001$ ) suggesting a significant non-random contribution to the between species variation in effect size. A possible factor resulting in such a contribution might be between species variation in differences in life-history perspectives of the parasitic and bourgeois tactic. In all species, bourgeois males are larger and have primary access to gravid females, whereas the parasitic males are subordinate and attempt to reproduce by 'sneaking' towards spawning events and releasing sperm. In both blennies species, ARTs are sequential, parasitic males being younger males and bourgeois males being older males (Oliveira et al. 2001b). In S. alpinus, individuals may shift between tactics depending on the social context (Sigurjónsdóttir \& Gunnarsson 1989). While in S. melops, tactics are fixed (Uglem et al. 2001, 2002). High investment in current reproduction at the cost of survival/immune system might be less beneficial for the parasitic tactics of blennies and $S$. alpinus than for $S$. melops because parasitic males of blennies and $S$. alpinus have the future prospect to switch to a bourgeois tactic and have primary access to spawning females.

In conclusion, although between tactic comparison of lymphocyte and androgen levels support the immunocompetence handicap hypothesis (Folstad $\&$ Karter 1992), individual lymphocyte levels did not correlate significantly with androgen levels, and the between tactic difference might be explained by a negative correlation between lymphocyte levels and 
body size. Therefore, it might be important to search for additional mechanisms other than regulation by androgens to better explain the natural variation in immunocompetence in fish with ARTs. Possible candidates are social modulation of the immune system because the social environment of parasitic and bourgeois males is very divergent, and life history stage-related modulation of the immune system because investment in survival might be beneficial for individuals that reproduce as parasitic males but may switch to become bourgeois males later in life.

\section{Acknowledgements}

The direction of the Parque Natural da Ria Formosa provided essential technical and logistical support. Tânia Oliveira helped with carrying out the radioimmunoassays. David Gonçalves, Magda Teles and Teresa Fagundes assisted during the fieldwork. We thank Annsi Vainikka, Donald Miles and an anonymous referee for improving the manuscript. A.F.H.R. was being supported by a post-doctoral fellowship from the Portuguese Foundation for Science and Technology (FCT) (SFRH/BPD/7143/2001). The research is additionally supported by FCT's Plurianual Program to R\&D Unit 331/94 and R\&D Unit 531/96. A.F.H.R. is certified to carry out animal experiments (DGV), and the procedures used in this study comply with the current laws of Portugal.

\section{Literature Cited}

Almada, V. C., Gonçalves, E. J., Santos, A. J. \& Baptista, C. 1994: Breeding ecology and nest aggregations in a population of Salaria pavo (Pisces: Blenniidae) in an area where nest sites are very scarce. J. Fish Biol. 45, 819-830.

Andersson, M. 1991: Sexual Section. Princeton Univ. Press, Princeton, NJ.

Bax, L., Yu, L. M., Ikeda, N., Tsuruta, H. \& Moons, K. G. M. 2006: Development and validation of MIX: comprehensive free software for meta-analysis of causal research data. BMC Medical Research Methodology 6, 50 pp.

Borg, B. 1994: Androgens in teleost fishes. Comp. Biochem. Physiol. 109C, 219-245.

Brantley, R. K., Wingfield, J. C. \& Bass, A. H. 1993: Sex steroid levels in Porichthys notatus, a fish with alternative reproductive tactics, and a review of the hormonal bases for male dimorphism among teleost fishes. Horm. Behav. 27, 332-347.

Deerenberg, C., Apanius, V., Daan, S. \& Bos, N. A. 1997: Reproductive effort decreases antibody responsiveness. P. Roy. Soc. Lond. B Bio. 264, 1021-1029.
Demas, G. E. 2004: The energetics of immunity: a neuroendocrine link between energy balance and immune function. Horm. Behav. 43, 75-80.

Dijkstra, P. D., Hekman, R., Schulz, R. W. \& Groothuis, T. G. G. 2007: Social stimulation, nuptial colouration, androgens and immunocompetence in a sexual dimorphic cichlid fish. Behav. Ecol. Sociobiol. 61, 599-609.

Folstad, I. \& Karter, A. J. 1992: Parasites, bright males, and the immunocompetence handicap. Am. Nat. 139, $603-622$.

Folstad, I. \& Skarstein, F. 1997: Is male germ line control creating avenues for female choice? Behav. Ecol. 8, 109-112.

Gonçalves, E. J., Almada, V. C., Oliveira, R. F. \& Santos, A. J. 1996: Female mimicry as a mating tactic in males of the blenniid fish Salaria pavo. J. Mar. Biol. Ass. U.K. 76, 529-538.

Gonçalves, D. M., Fagundes, T. \& Oliveira, R. F. 2003: Reproductive behaviour of sneaker males of the peacock blenny. J. Fish Biol. 63, 528-532.

Gonçalves, D. M., Teles, M., Alpedrinha, J. \& Oliveira, R. F. 2008: Brain and gonadal aromatase activity and steroid hormone levels in female and polymorphic males of the peacock blenny Salaria pavo. Horm. Behav. 54, $717-725$.

Kime, D. E. \& Manning, N. J. 1982: Seasonal patterns of free and conjugated androgens in the brown trout Salmo trutta. Gen. Comp. Endocr. 48, 222-231.

Klasing, K. C. 2004: The cost of immunity. Acta Zool. Sinica 50, 961-969.

Kurtz, J., Kalbe, M., Langefors, A., Mayer, I., Milinski, M. \& Hasselquist, D. 2007: An experimental test of the immunocompetence handicap hypothesis in a teleost fish: 11-ketotestosterone suppresses innate immunity in three-spined sticklebacks. Am. Nat. 170, 509—519.

Lailvaux, S. P. \& Irschick, D. J. 2006: A functional perspective on sexual selection: insights and future prospects. Anim. Behav. 72, 263-273.

Law, W.-Y., Chen, W.-H., Song, Y. L., Dufour, S. \& Chang, C.-F. 2001: Differential in vitro suppressive effects of steroids on leukocyte phagocytosis in two teleosts, tilapia and common carp. Gen. Comp. Endocr. 121, 163-172.

Liljedal, S. \& Folstad, I. 2003: Milt quality, parasites, and immune function in dominant and subordinate Arctic charr. Can. J. Zool. 81, 221-227.

Miles, D. B., Sinervo, B., Hazard, C., Svensson, E. I. \& Costa, D. 2007: Relating endocrinology, physiology and behaviour using species with alternative mating strategies. Funct. Ecol. 21, 653-665.

Nava, M. P., Veiga, J. P. \& Puerta, M. 2001: White blood cell counts in house sparrows (Passer domesticus) before and after moult and after testosterone treatment. Can. J. Zool. 79, 145-148. 
van Noordwijk, A. J. \& de Jong, G. 1986: Acquisition and allocation of resources: their influence on variation in life history tactics. Am. Nat. 128, 137-142.

Norris, K. \& Evans, M. R. 2000: Ecological immunology: life history trade-offs and immune defense in birds. Behav. Ecol. 11, 19-26.

Oliveira, R. F. 2006: Neuroendocrine mechanisms of alternative reproductive tactics in fish. In: Fish Physiology, Vol. 24: Behaviour: Interactions with Physiology (Sloman, K. A., Wilson, R. W. \& Balshine, S., guest eds; Hoar, W. S., Randall, D. J. \& Farrell, A. P., series eds). Elsevier, New York, pp. 297-357.

Oliveira, R. F. \& Gonçalves, D. M. 2008: Hormones and social behaviour of teleost fish. In: Fish Behaviour (Magnhagen, C., Braithwaite, V. A., Forsgren, E. \& Kapoor, B. G., eds). Science Publishers Inc, Enfield, $\mathrm{NH}$, pp. 61-150.

Oliveira, R. F., Almada, V. C., Gonçalves, E. J., Forsgren, E. \& Canário, A. V. M. 200la: Androgen levels and social interactions in breeding males of the peacock blenny. J. Fish Biol. 58, 897-908.

Oliveira, R. F., Canário, A. V. \& Grober, M. S. 2001b: Male sexual polymorphism, alternative reproductive tactics, and androgens in combtooth blennies (pisces: blenniidae). Horm. Behav. 40, 266-275.

Oliveira, R. F., Carneiro, L. A. \& Canário, A. V. 2005: No hormonal response in tied fights. Nature 437, 207-208.

Oliveira, R. F., Canário, A. V. M. \& Ros, A. F. H. 2008a: Hormones and alternative reproductive tactics in vertebrates. In: Alternative Reproductive Tactics: An Integrative Approach (Oliveira, R. F., Taborsky, M. \& Brockmann, H. J., eds). Cambridge Univ. Press, Cambridge, pp. 132-173.

Oliveira, R. F., Taborsky, M. \& Brockmann, J. 2008b: Alternative Reproductive Tactics: An Integrative Approach. Cambridge Univ. Press, Cambridge.

Roberts, M. L., Buchanan, K. L. \& Evans, M. R. 2004: Testing the immunocompetence handicap hypothesis: a review of the evidence. Anim. Behav. 68, 227-239.

Robertson, O. H. 1961: Prolongation of the life span of Kokanee salmon (Oncorhynchus nerka kennerlyi) by castration before beginning of gonad development. PNAS 47, 609-621.

Ros, A. F. H., Bouton, N., Santos, R. S. \& Oliveira, R. F. 2006a: Alternative male reproductive tactics and the immunocompetence handicap in the Azorean rockpool blenny, Parablennius parvicornis. Proc. R. Soc. Lond., B, Biol. Sci. 273, 901-909.

Ros, A. F. H., Ferreira, C., Santos, R. S. \& Oliveira, R. F. 2006b: Regulation of immunocompetence by different androgen metabolites in a blenny with alternative reproductive tactics. J. Exp. Zool. 305A, 986-994.
Ruchon, F., Laugier, T. \& Quignard, J. P. 1995: Alternative male reproductive strategies in the peacock blenny. J. Fish Biol. 47, 826-840.

Santos, R. S., Nash, R. D. M. \& Hawkins, S. J. 1995: Age, growth and sex ratio of the Azorean rock-pool blenny, Parablennius sanguinolentus parvicornis. J. Mar. Biol. Assoc. UK 75, 751-754.

Scott, A. P. \& Vermeirssen, E. L. M. 1994: Production of conjugated steroids by teleost gonads and their role as pheromones. In: Perspectives in Comparative Endocrinology (Davey, K. G., Peter, R. E. \& Tobe, S. S., eds). National Research Council of Canada, Ottawa, pp. 645-654.

Sheldon, B. C. \& Verhulst, S. 1996: Ecological immunology: costly parasite defences and trade-offs in evolutionary ecology. Trends Ecol. Evol. 11, 317-321.

Sigurjónsdóttir, H. \& Gunnarsson, K. 1989: Alternative mating tactics of arctic charr, Salvelinus alpinus. Environ. Biol. Fishes 26, 159-176.

Slater, C. H. \& Schreck, C. B. 1997: Physiological levels of testosterone kill salmonid leukocytes in vitro. Gen. Comp. Endocr. 106, 113-119.

Slater, C. H. \& Schreck, C. B. 1998: Season and physiological parameters modulate salmonid leucocyte androgen receptor affinity and abundance. Fish Shellfish Immunol. 8, 379-391.

Slater, C. H., Fitzpatrick, M. S. \& Schreck, C. B. 1995: Characterization of an androgen receptor in salmonid lymphocytes: possible link to androgen-induced immunosuppression. Gen. Comp. Endocr. 100, 218-225.

Summerfelt, R. C. \& Smith, L. S. 1990: Anesthesia, surgery and related techniques. In: Methods for Fish Biology (Schreck, C. B. \& Moyle, P. B., eds). American Fisheries Society, Bethesda, MD, pp. 213-218.

Taborsky, M. 2008: Alternative reproductive tactics in fish. In: Alternative Reproductive Tactics - An Integrative Approach (Oliveira, R. F., Taborsky, M. \& Brockmann, H. J., eds). Cambridge Univ. Press, Cambridge, pp. $251-299$.

Uglem, I., Galloway, T. F., Rosenqvist, G. \& Folstad, I. 2001: Male dimorphism, sperm traits and immunology in the corkwing wrasse (Symphodus melops L.). Behav. Ecol. Sociobiol. 50, 511-518.

Uglem, I., Mayer, I. \& Rosenqvist, G. 2002: Variation in plasma steroids and reproductive traits in dimorphic males of corkwing wrasse (Symphodus melops L.). Horm. Behav. 41, 396-404.

Vainikka, A., Jokinen, E. I., Kortet, R. \& Taskinen, J. 2004: Gender- and season-dependent relationships between testosterone, oestradiol and immune functions in wild roach. J. Fish Biol. 64, 227-240.

Vainikka, A., Jokinen, E. I., Kortet, R., Paukku, S., Pirhonen, J., Rantala, M. J. \& Taskinen, J. 2005: Effects of testosterone and $ß$-glucan on immune functions in tench. J. Fish Biol. 66, 348-361. 
Viney, M. E., Riley, E. M. \& Buchanan, K. L. 2005: Optimal immune responses: immunocompetence revisited. Trends Ecol. Evol. 20, 665-669.

Watts, M., Munday, B. L. \& Burke, C. M. 2001: Immune responses of teleost fish. Aust. Vet. J. 79, 570-574.

Yada, T. \& Nakanishi, T. 2002: Interaction between endocrine and immune systems in fish. Int. Rev. Cytol. 220, 35-92.
Zander, C. D. 1986: Blenniidae. In: Fishes of the NorthEastern Atlantic and the Mediterranean (Whitehead, P. J. P., Bauchot, M.-L., Hureau, J.-C., Nielsen, J. \& Tortonese, E., eds). Unesco, Paris, pp. 1096-1112. Zohar, Y. \& Billard, R. 1984: Annual and daily changes in plasma gonadotropin and sex steroids in relation to teleost gonad cycles. T. Am. Fish. Soc. 113, $444-451$. 